\title{
Improved and innovated universal DAQ microcontroller unit
}

\author{
Petr Dostálek, Libor Pekař, and Pavel Navrátil
}

\begin{abstract}
This paper is aimed at the description of hardware design, software equipment and the functionality of the second evolution of the intelligent multipurpose input/output microcontroller converter and control unit designed and assembled by the authors. Preceding stages of the unit development are concisely overviewed first, the deficiencies of which give rise to the primary motivation of this contribution. Then separate hardware parts of the novel unit are described in detail including electronic schematic diagrams. The device firmware and software capabilities are introduced as well. The advantages of the unit are highlighted compared to older versions. Its functionality, performance and efficiency are then verified by a laboratory control-related dynamic responses measurement example. In the contrary to previous evolutions, a more compact hardware design, increased $A / D$ and $D / A$ converter resolutions, added USB communication capability, better and more accurate analog circuits with more advanced operation amplifiers, the use of OLED instead of LCD display, the pulse-width modulated signal generated by the microcontroller unit itself can be considered among the most important improvements. Moreover, the direct use of the serial link may reduce noise significantly and makes the device more universal.
\end{abstract}

Keywords-Data acquisition card, engineering education, microcontroller unit, temperature control

\section{INTRODUCTION}

$\mathbf{T}$ EMPERATURE measurement and control modules represent one of the most common laboratory appliances in the computer and engineering educational process [1]-[3]. Among the main reasons for that, temperature can be easily and non-expensively measured and processed for a wide range of values, heating plants are sufficiently slow and their models are usually not very complex such that students can simply design an appropriate controller, and temperature control is pervasive in industry from the point of view of the practice [4][7].

Hand in hand with that, signals and data ought to be processed and evaluated via data acquisition units (DAQ), converters and computers [3], [4], [8]. In addition, hardware (HW) devices have to be equipped with proper firmware with and ad-hoc or general-purpose software (SW) [7], [9].

Until 2014, obsolete, dangerous and non-compact modular units had been used within the laboratory educational process in subjects related to automation and control engineering at the home institution of the authors. There was a necessity to replace them by a modern low-cost modular microcontroller converter and control unit. Although there were available standard analog converters for many types of Resistance Temperature Detector (RTD) elements with unified voltage or current output signals on the industry market, they were not suitable for our applications due to a different concept of the intelligent converter unit. Besides the basic functionality of the RTD converter, we also needed a digital communication

This work was supported by the Ministry of Education, Youth and Sports of the Czech Republic within the National Sustainability Programme project No. LO1303 (MSMT-7778/2014).

P. Dostálek, L. Pekař, and P. Navrátil are with the Department of Automation and Control Engineering, Faculty of Applied Informatics, Tomas Bata University in Zlín,, Czech Republic (e-mail: pekar@fai.utb.cz). interface directly connected to the personal computer without a special data acquisition card. Such a combined converter device including power digital output was not commonly available in the compact form, as required in the educational process. Moreover, the price was a key parameter for decision making.

Thus, we have designed, developed and assembled a new more compact yet modular low-cost microcomputer input/output (I/O) laboratory module for signal converting, data acquisition and control of the temperature educational plant [3]. However, some problems and imperfections with this first evolution of the innovated converter unit have persisted; hence, we have decided to re-design it such that the compactness, universality noise-reduction and the accuracy have been enhanced.

The rest of the paper is organized as follows: Section II provides the reader with a design history overview and the motivation of this paper. HW equipment of the designed and assembled unit is described in section III. For better clarity, overview tables help reader to make a comparison between particular evolutions. Operational properties and the outline of SW issues can be found in section IV. In Section V, the functionality and performance capabilities of the unit are shown and proved by the measurement of the step and control responses. The Conclusion section summarizes the paper and suggests some future improvements.

\section{PReceding EVOlutions OVERVIEW}

The laboratory of automation and control engineering at Tomas Bata University in Zlin serves student to practice their knowledge in Automation, System Theory, Identification and other subjects. Since 80 s of the last century until 2014, every single seat in the laboratory room was equipped with a central computer (PC) with Advantech PCI 1171 acquisition card connected to the I/O converter and control unit (see Fig. 1) constituting an interface between the PC and the controlled heating plant (see Fig. 2). Two plants were connected with one such a device. This appliance, however, suffered from some deficiencies that disabled to keep using it for modern control and identification educational tasks. Namely, its slacken modules, that could be accidentally removed, may have caused harm to students and teachers since the unit was powered by $230 \mathrm{~V}$ AC from mains, which does not meet current working and safety conditions. Moreover, original spare parts are almost impossible to be acquired nowadays. The absence of a central microcomputer did not enable users to set anything digitally, and only a simple 3-digit 7-segment LED display provided rough measurement data. Two built-in converter cards for processing the signal from Pt100 sensors provided the user with the normalized analog signal within the range of $0-10 \mathrm{~V}$ DC. A rheostat in the heating plant body was warmed up by $24 \mathrm{~V}$ AC control input. 
In 2014, a modern modular unit prototype was designed and assembled [1], see Fig. 3 for its appearance and Fig. 4 for the functional block scheme. On one hand this innovation has brought the preservation of basic functional properties of the obsolete appliance, which gives rise to the so-called compatibility mode. On the other hand, it has improved many other attributes; namely, the unit has been powered by the safe $24 \mathrm{~V}$ AC input, equipped with a central microcontroller board, LCD display, a 3x3 keyboard and the RS232 serial interface. A firmware implementing basic input and output functions, diagnostic and peripheral services has been developed in addition, the serial interface could cooperate e.g. with MATLAB $^{\circ}$. The unit has had a modern appearance, is compact, intelligent and safe and can be easily modularly extended. The prize is among other crucial benefits of this first evolution: Components and manufacturing expanses of the designed device have not exceeded $350 \$$ in total.

There have been, however, still many features that might be improved. For instance, the device could not process a unified $0-10 \mathrm{~V}$ DC input - this feature would make the device more universal and may extend the area of its applicability. In addition, there have been a relatively high noise and low measurement accuracy levels mainly due to the used converter resolution. The modularity of this evolution of the unit has not also been excellent since there have been a bunch of wiring inside the device (Fig. 5). Thus, the second evolution has been designed and the prototypal appliance assembled.

\section{CONVERTER/CONTROL UnIT HARDWARE}

In this section, the overall conception and a concise description of HW equipment the second evolution is introduced. If necessary, the differences from the first to the second evolution (or even against the obsolete appliance) are given to the reader.

Basic general HW equipment properties of all the evolutions are summarized in Table I. Hardware design of the intelligent I/O control and converter unit device for the evaluation of signals (not only) from resistance-based temperature sensors is adapted to high accuracy and easy functional expansion in future applications by simply adding of modules with required features.

In addition, it is capable to generate the power control signal which can directly drive heating elements. This is achieved by splitting the converter unit into the two basic parts:

- The main board consisting of the master microcontroller (MCU), communication interfaces (COM), stabilized power supplies (PSU) and expansion connectors for input and output modules.

- Expansion modules that can be inserted into the connectors of the main board. Basically, three types of modules can be implemented: (1) Input modules converting analog signals from sensors to digital signals and processing a digital signal from a PC, (2) output modules converting digital signals back to analog ones fed to a card in a PC, or (3) those giving digital power outputs.

A scheme of basic blocks introduced above can be seen in Fig. 6.

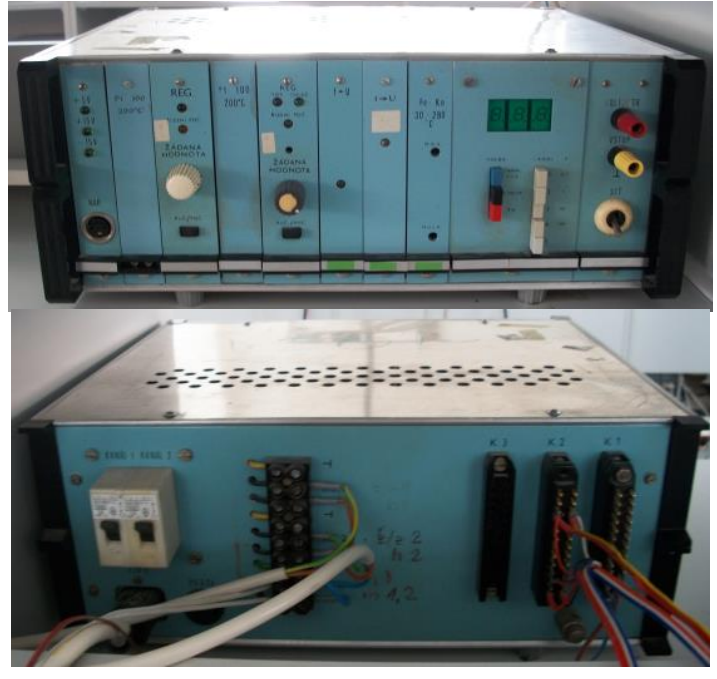

Fig. 1. The front-side (up) and back-side (down) appearance of the former obsolete I/O converter and control unit.

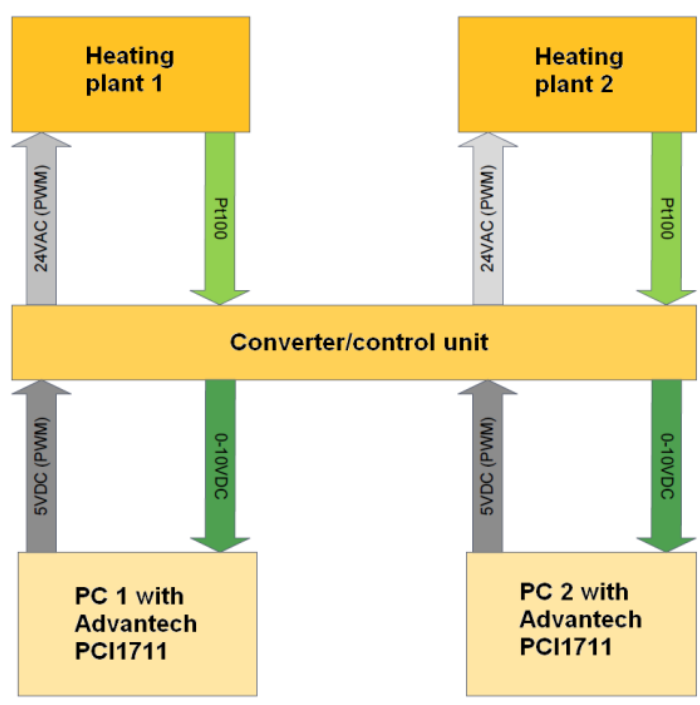

Fig. 2. A scheme of the laboratory heating measurement and control system configuration.

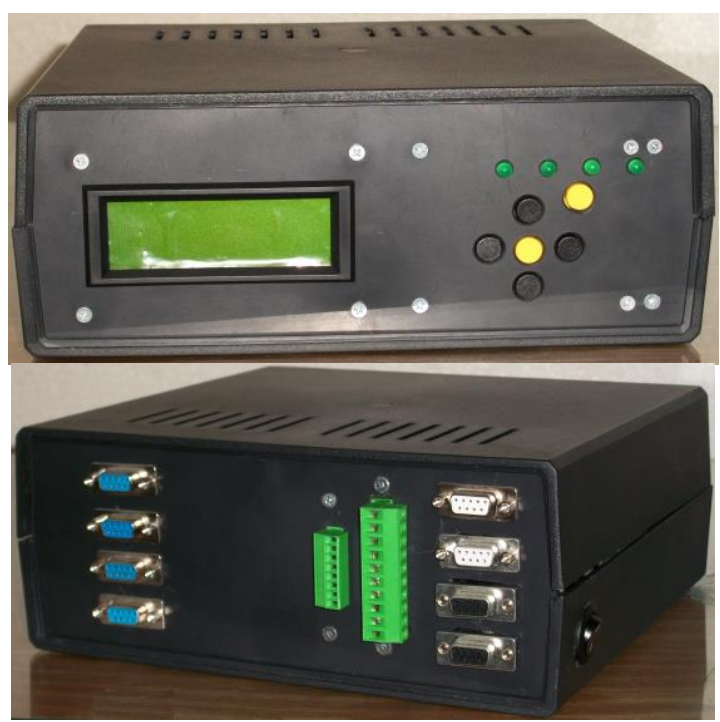

Fig. 3. The appearance of the first evolution of the module - the front (up) and the back side (down). 


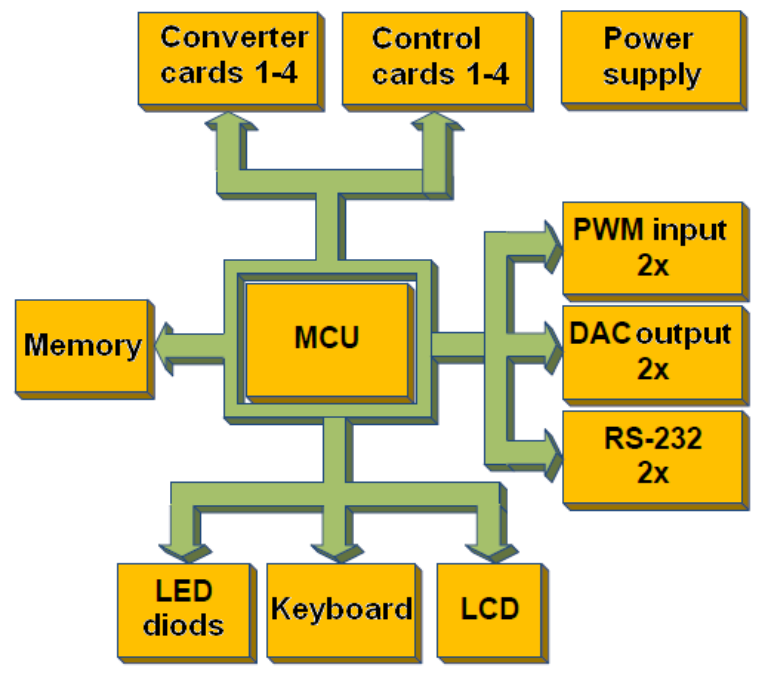

Fig. 4. A block scheme of the first evolution of the module.

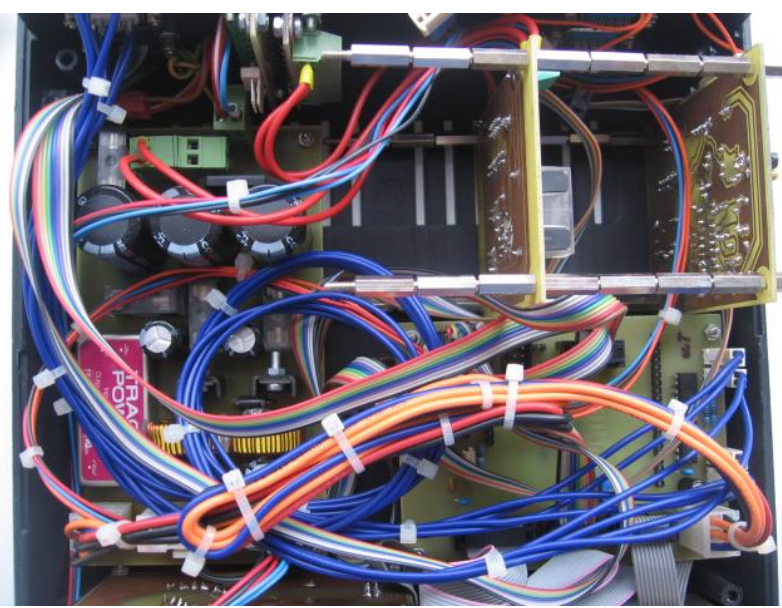

Fig. 5. Wiring inside the unit of the first evolution.

Note that the conception of the first evolution was rather different. Namely, converter and control expansion modules instead of input and output one were used. Moreover, the modules layout was of a "sandwich" structure (including a display module, a keyboard module, a power supply control module and some auxiliary modules, in addition), whereas the new unit uses the compact integrating main board and slots for fixing expansion modules, which is more comfortable for users.

\section{A. Main board design}

Main board design is based on NXP MCF51AC128 microcontroller [10] in the QFP64 package (as in the preceding evolution) performing all operations of the intelligent converter unit. It is a member of Flexis 32-bit ColdFire ${ }^{\circledR}$ V1 microcontrollers' family enabling a simple migration from 8bit Flexis MCUs to 32-bit one due to pin-to-pin compatibility. Such microcontrollers are suitable for entry-level applications that do not need special features of ColdFire V2 core.

The correct program function is monitored by an integrated watchdog Computer Operating Properly (COP) system, and illegal operational code and address detection are checked by programmable reset or exception response. The Central Processor Unit (CPU) can work at the frequency up to $50.33 \mathrm{MHz}$, the maximum internal bus frequency is $24 \mathrm{MHz}$ at the supply voltage range of $2.7-5.5 \mathrm{~V}$.
TABLE I

BASIC HW EQUIPMENT

\begin{tabular}{cccc}
\hline \hline Equipment & Obsolete unit & Evolution 1 & Evolution 2 \\
\hline Power supply & 230V AC & 24V AC & 24V AC \\
\hline Microcontroller & none & NXP & NXP \\
& MCF51AC128 & MCF51AC128 \\
\hline CPU clock rate & none & $50.33(24) \mathrm{MHz}$ & $50.33(24) \mathrm{MHz}$ \\
and supply voltage & @ 2.7-5.5V & @ 2.7-5.5V \\
\hline Keyboard unit & none & $3 \times 3$ & $3 \times 1$ \\
\hline Display unit & LED 3-digit & STN LCD 4x20 & OLED 4x20 \\
& numeric & alphanumeric & alphanumeric \\
\hline \hline
\end{tabular}

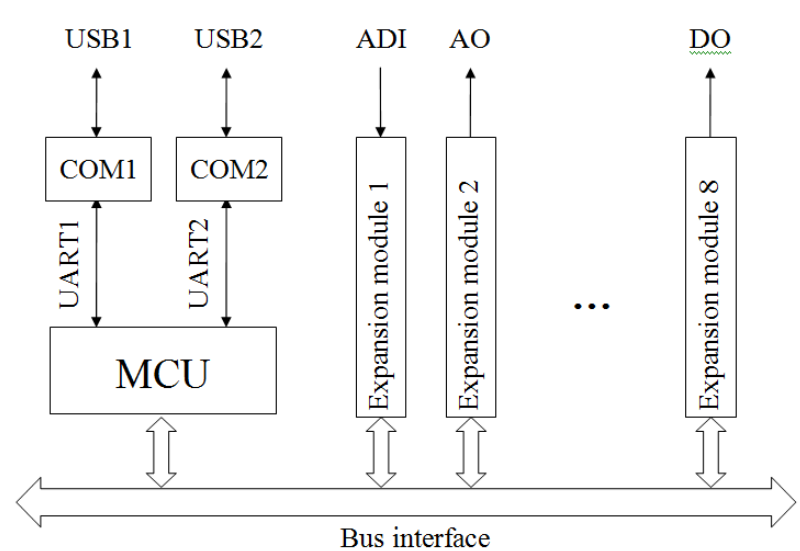

Fig. 6 A block scheme of the intelligent converter unit.

The communication with a higher control or supervision systems is provided by two FT232BM USB Universal Asynchronous Receiver/Transmitter (UART) Integrated Circuits (ICs). They are capable to communicate at TTL levels with data transfer rates up to $3 \mathrm{MBd}$. An on-chip integrated transmit/receive buffer with the capacity of $128 \mathrm{~B}$ and $384 \mathrm{~B}$ enables high data throughput. FT232BM operates from a single power supply with the voltage of $5 \mathrm{~V}$. The USB I/O interface is supplied from an integrated $3.3 \mathrm{~V}$ voltage regulator. Due to the integrated level converter for UART I/O signals, it is possible to connect it with logic circuits operating at $3.3 \mathrm{~V}$ or $5 \mathrm{~V}$. Both communication interfaces are realized in the manufacturer recommended wiring for a self-powered application with the $5 \mathrm{~V}$ input/output interface.

The connected optional EEPROM memory $93 \mathrm{C} 46$ of the size of $128 \mathrm{~KB}$ can be used for the storage of the USB Vendor Identification (VID), the device class definition for Physical Interface Devices (PID), the serial number and product description strings.

The clock signal is generated externally by a crystal oscillator with the frequency of $6 \mathrm{MHz}$. USB1 and USB2 UART I/O interfaces are connected to corresponding UART0 and UART1 pins of the main microcontroller.

Expansion modules can be inserted into eight 30pin doublerow connectors including all signals necessary for their function. The connectors provide the voltage source of $5 \mathrm{~V}$ for digital circuits and that of $\pm 15 \mathrm{~V}$ DC for analog ones, the serial peripheral interface for communication with the master microcontroller, and an 8-input/8-output general purpose digital interface that can be utilized for the internal logic control of the connected modules. The active expansion connector is selected by the main microcontroller in the 
cooperation with the 3 -to- 8 line decoder $74 \mathrm{HC} 138$, the outputs of which provide eight board-select signals. Only one expansion module can be in the active state at the moment and it communicates with the microcontroller via the Serial Peripheral Interface (SPI) interface, whereas other modules must stay in the high impedance (inactive) state.

The main board also provides a parallel interface for the OLED display control consisting of 4 data lines (DB4 - DB7), 3 control signals (RW, RS, E) and $+5 \mathrm{~V}$ power supply lines. It is supplied by a $24 \mathrm{~V}$ AC voltage source which is commonly used in control systems for sensors and actuators power supplies. The rectified input voltage is converted by two DCDC converters to $5 \mathrm{~V}$ with the output power of $6 \mathrm{~W}$ for logic circuits and $\pm 15 \mathrm{~V}$ for analog circuits. Schematics of the main board are depicted in Figs. 7 and 8.

\section{B. Expansion modules design}

The converter unit hardware configuration is determined by installed expansion modules. Each module type has its identifier which can be read by the main microcontroller from the bus interface. During the initialization phase, all expansion slots are scanned, and consequently, connected modules are auto-detected and correctly initialized. The designed main board enables to connect up to 8 expansion modules.

The following types of modules are currently available (as introduced above):

- Analog and digital inputs (AI, DI)

- Analog outputs (AO)

- $\quad$ Power digital outputs (DO)

\section{1) AI and DI module}

The module is equipped with two analog converters for Pt100 type resistance sensors over 0 to $400{ }^{\circ} \mathrm{C}$ temperature range and with two AIs over the unified voltage range from 0 to $10 \mathrm{~V}$. All AIs are protected against voltage overload by protection diodes. Analog signals are converted by using the 14-bit analog-to-digital (DA) converter TLC3544DW to digital values which are transferred by a SPI to the main microcontroller. High temperature stability of analog circuits is achieved by the utilization of the high precision operational amplifiers OPA4277. The reference voltage of $3 \mathrm{~V}$ for analog and digital circuits is provided by the voltage reference IC AD780ANZ. A bus interface of the module is controlled by two octal 3 -state bus transceivers $74 \mathrm{HC} 245$. The module is also capable to processes two TTL compatible digital inputs from a PC with the Advantech card.

Schematic of the analog and digital inputs module is depicted in the Fig. 9.

2) Analog outputs module (AO)

The module is based on two 16-bit digital-to-analog (DA) converters DAC8830 with the SPI communication interface. The converter output is amplified by a non-inverting amplifier with the gain of 4 resulting in the final output voltage range from 0 to $10 \mathrm{~V}$. High temperature stability of analog circuits is achieved by the utilization of the OPA2277PA operational amplifier again. The reference voltage of $2.5 \mathrm{~V}$ for DA converter is provided by the same voltage reference as for the module of AIs and DIs.

A schematic of the AOs module is depicted in the Fig. 10.
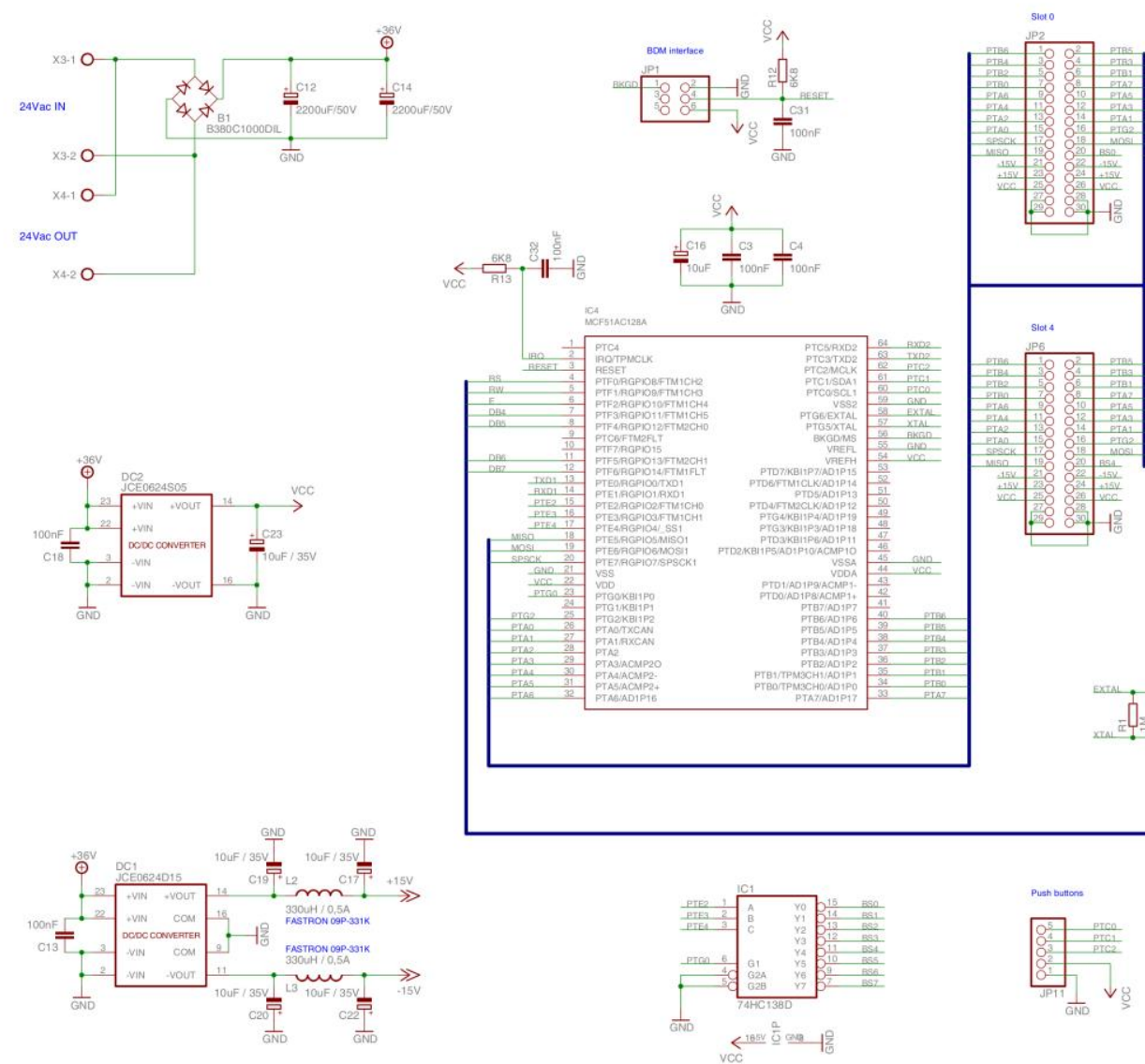

Fig. 7. A schematics of the mainboard - part 1: main microcontroller, power supplies, expansion connectors. 


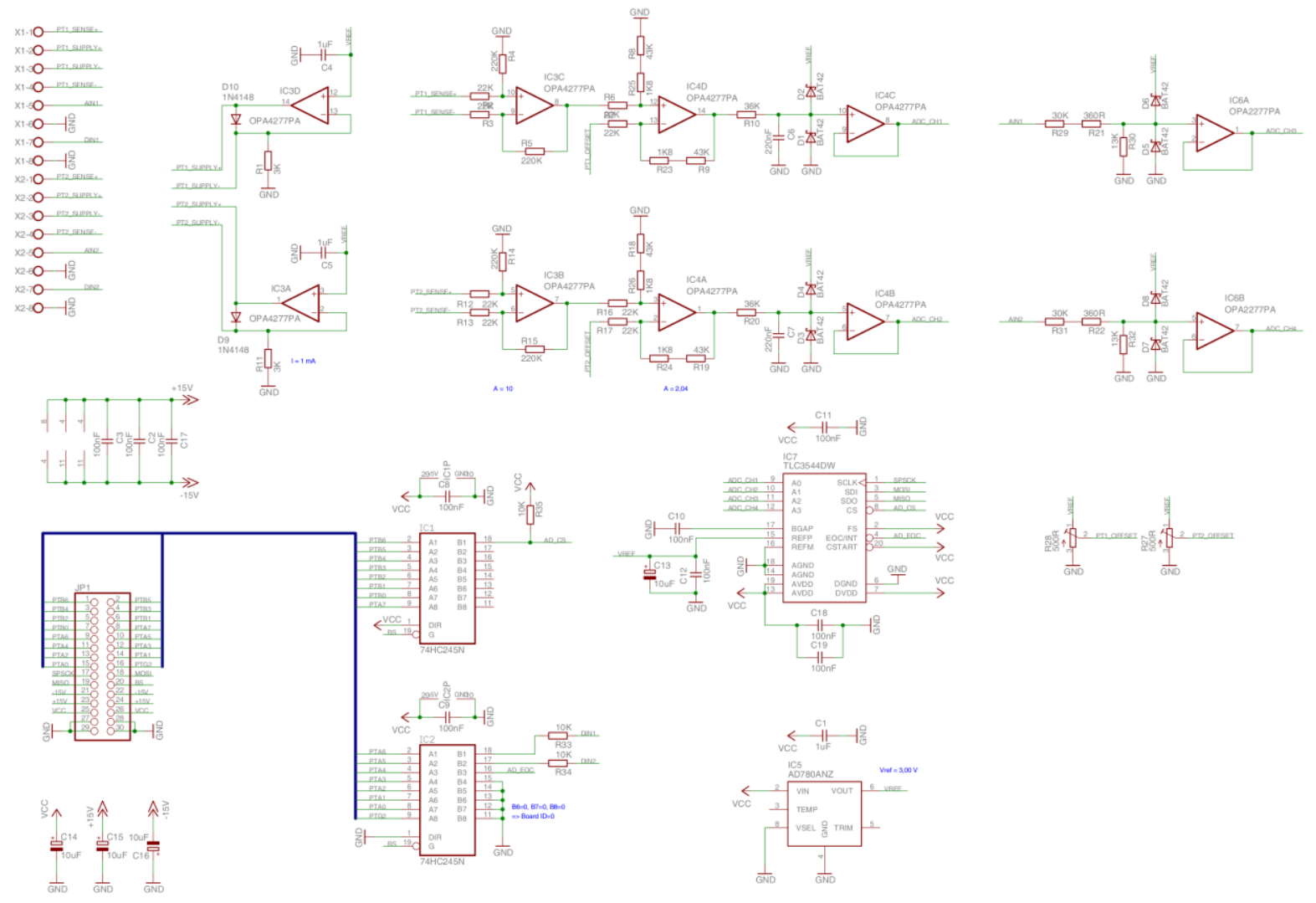

Fig. 8. A schematics of the main board - part 2: USB UART interfaces.

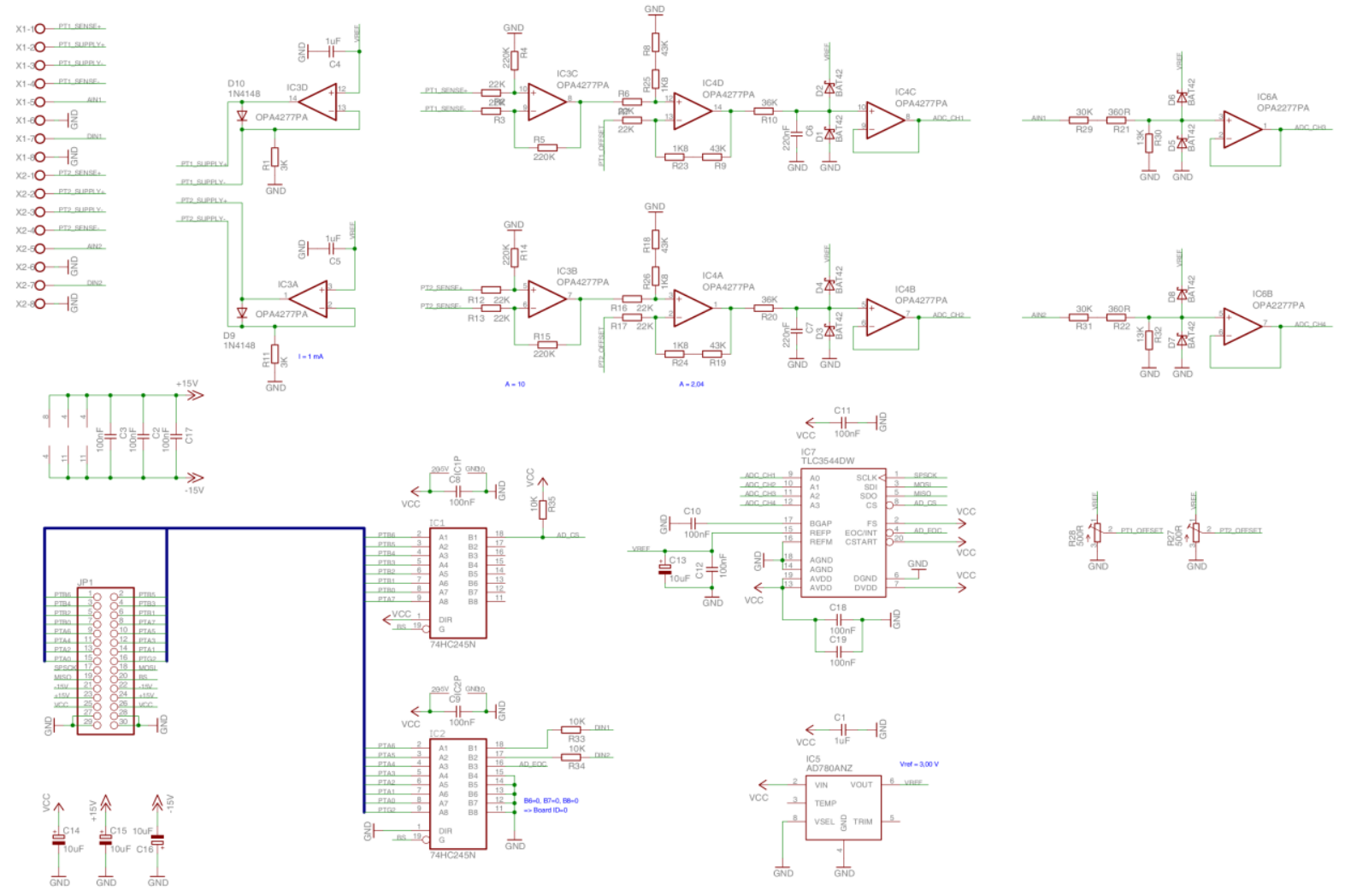

Fig. 9. A schematic of the analog and digital inputs module. 

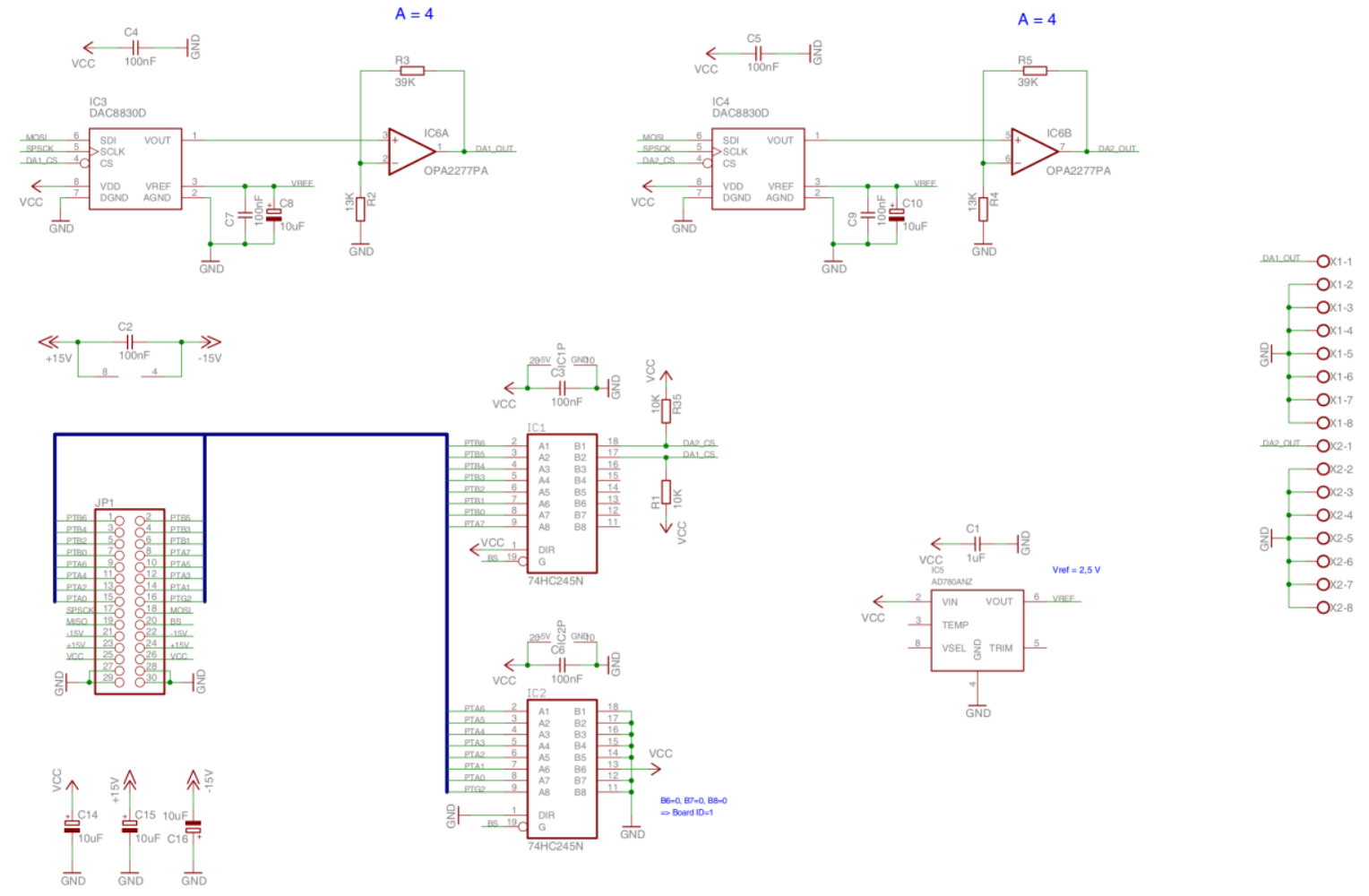

Fig. 10. A schematic of the analog outputs module.

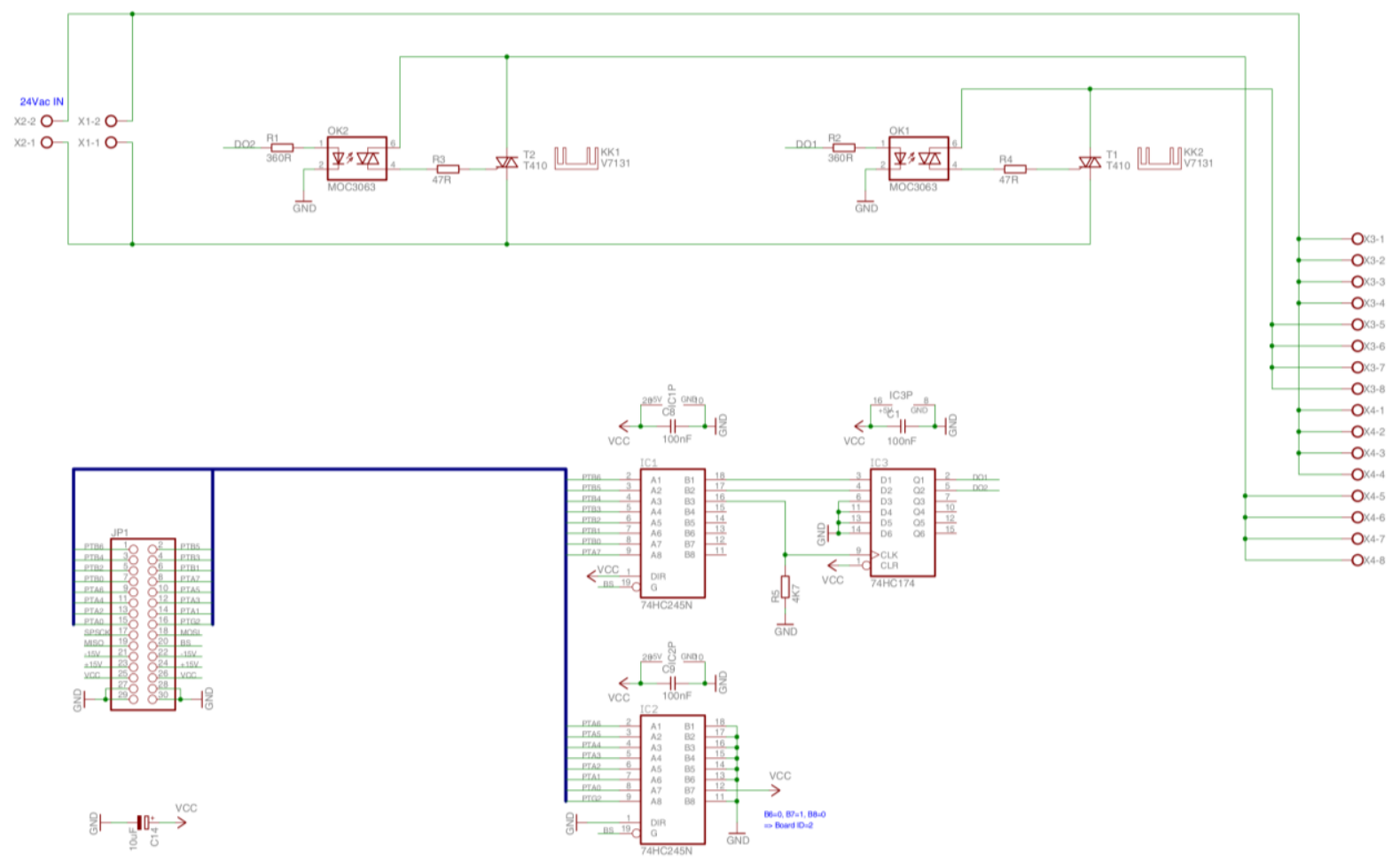

Fig. 11. A schematic of the power digital output module. 


\section{3) Power digital outputs module (DO)}

The main function of this module is to switch two resistance loads with the power supply voltage of $24 \mathrm{~V}$ AC. It utilizes the T410 power triacs that are separated from sensitive digital control circuits by MOC3063 optotriacs. The power triac T410 is capable to handle current up to $4 \mathrm{~A}$ RMS with the small turn-on gate current of $10 \mathrm{~mA}$ enabling its control by using the standard TTL logic. Its maximum operating voltage is $600 \mathrm{~V}$. Control signals for triacs are generated by the D-type flip-flop $74 \mathrm{HC} 174$ in which the main microcontroller desired value of the corresponding digital output is stored. A bus interface of the module is controlled by transceivers of the same type as for the AIs and DIs module. PWM pulses received by the unit from the Advantech card in a PC are simply copied to the output (in the compatibility mode), or generated by the microcontroller (in the analog input control signal type mode or direct serial control mode) with a high timing precision.

A schematic of the power digital output module is depicted in the Fig. 11. In Table II, selected HW properties and equipment are highlighted and summarized to provide the reader with the comparison of both evolutions.

The overall external appearance of the developed second evolution of the converter unit is pictured in Fig. 12. There can also be seen the 4-line alphanumeric OLED display WEH002004A and a simple 3-key board with yellow backlight for moving in the menu, confirmation and cancellation in the figure.

\section{OPERATIONAL Properties AND DEVICE FIRMWARE}

The converter unit can work in 3 modes of operation. In the first mode (mode 1) also called "the compatibility mode", it works in the same way as the old analog converter unit: A PC equipped with a PCI DAQ card generates digital TTL PWM control signal simply send to the converter unit, the power digital output of which is consequently connected to the heating element of the laboratory heating plant. The temperature value of the element is measured by Pt100 type RTD which is connected to the corresponding analog input of the converter unit.

TABLE II

HW COMPARISON

\begin{tabular}{|c|c|c|}
\hline $\begin{array}{l}\text { Property or } \\
\text { equipment }\end{array}$ & Evolution 1 & Evolution 2 \\
\hline $\begin{array}{l}\text { Maximum number } \\
\text { of modules }\end{array}$ & $\begin{array}{l}4 \mathrm{x} \text { converter } \\
4 \mathrm{x} \text { control }\end{array}$ & 8x ADI, AO, DO \\
\hline $\begin{array}{l}\text { Number of channels } \\
\text { per module }\end{array}$ & 2 & 2 \\
\hline $\begin{array}{l}\text { Power supply } \\
\text { Display control } \\
\text { Keyboard control }\end{array}$ & $\begin{array}{l}\text { On a separate } \\
\text { module }\end{array}$ & On the main board \\
\hline $\begin{array}{l}\text { Pt100 sensors } \\
\text { temperature range } \\
\text { and configuration }\end{array}$ & $\begin{array}{l}0 \text {-300 }{ }^{\circ} \mathrm{C} \\
\text { 2-wire }\end{array}$ & $\begin{array}{l}0-400{ }^{\circ} \mathrm{C} \\
\text { 4-wire }\end{array}$ \\
\hline $\begin{array}{l}\text { Communication } \\
\text { interface }\end{array}$ & $\begin{array}{c}\text { RS232 } \\
\text { on a separate module }\end{array}$ & $\begin{array}{c}\text { USB } \\
\text { on the main board }\end{array}$ \\
\hline $\begin{array}{l}\text { AD converter } \\
\text { resolution }\end{array}$ & $12 \mathrm{~b}$ & $14 \mathrm{~b}$ \\
\hline $\begin{array}{l}\text { DA converter } \\
\text { resolution }\end{array}$ & $12 \mathrm{~b}$ & $16 \mathrm{~b}$ \\
\hline DO parameters & $\begin{array}{l}\text { 24V/1A AC } \\
\text { 8bit PWM resolution }\end{array}$ & $\begin{array}{l}24 \mathrm{~V} / 2.5 \mathrm{~A} \mathrm{AC} \\
\text { min.10bit up to } 32 \mathrm{bit} \\
\text { PWM resolution }\end{array}$ \\
\hline
\end{tabular}

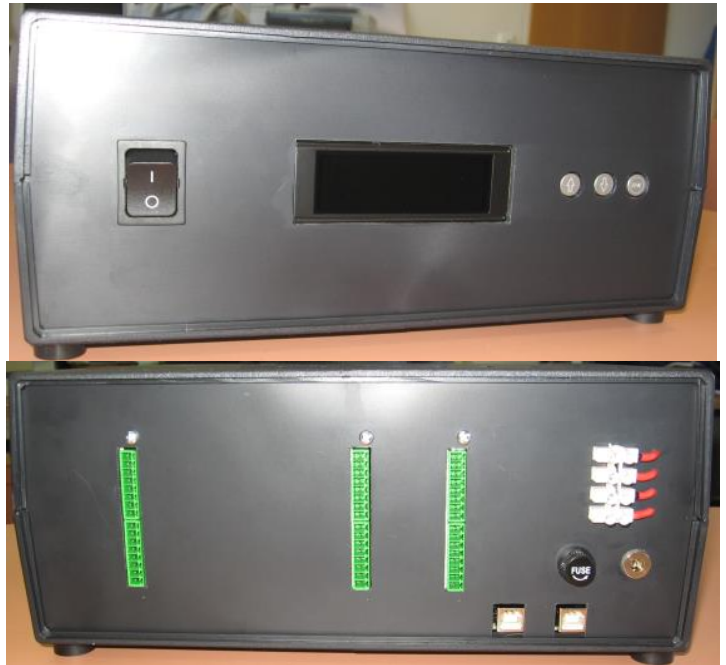

Fig. 12. The appearance of the second (new, herein described) evolution of the module - the front (up) and the back side (down).

The amplified analog signal is converted to a digital one by the $14 \mathrm{~b} \mathrm{~A} / \mathrm{D}$ converter and filtered in the 16-stage averaging filter, and then converted back to the unified analog output signal by the $16 \mathrm{~b}$ D/A converter followed by an amplifier. This unified analog output signal with the range of 0 to $10 \mathrm{~V}$ then enters a DAQ card of the control PC.

The second operation mode (mode 2) improves mode 1 in the control signal part. A digital PWM signal is replaced by the unified analog signal which is transformed to the precise timed digital PWM signal with the duty cycle proportional to the input voltage, in the converter unit. The signal period can be set by the user in the settings menu of the unit. The advantage of this mode consists in lower demands on the strict real-time processing on the control PC side.

In the last one (mode 3), the converter unit works as a data acquisition device where the PC is connected by using the USB interface. Control signals and measured values are transferred fully digitally without the necessity of any DAQ card in the PC. Converter unit functions are accessed through $16 \mathrm{~b}$ registers which are mapped to the main microcontroller memory.

The device firmware was written in the Freescale (NXP) CodeWarrior integrated development environment for microcontrollers in $\mathrm{C}$ language with the utilization of Processor Expert peripheral components. The software consists of the two parts: the main program routine and interrupts service routines.

\section{A. Main program routine}

The main program routine is started after power-up of the converter unit. First of all, Processor Expert function PE_low_level_init() is executed which initializes the CPU, all used hardware components and corresponding internal data structures. After this initial initialization, a user program is executed that has to detect the source of the system restart first. If it is the power on reset (POR), OLED display hardware is initialized otherwise this step is skipped because it has already been initialized. Then, the expansion board detection process follows during which internal data structures are updated and all boards are prepared for the correct functioning. If any error occurs or a wrong configuration is discovered during this phase, the device is halted with a corresponding error message on the display. 
The information welcome text and firmware version is displayed for two seconds in case of the successful startup sequence. The next program code runs in an infinite loop in which the following operations are sequentially treated:

- Process user input from the keyboard

- Display required data

- Compute the current PWM duty for digital outputs

- Process commands from both serial interfaces

- Write computed values to outputs

\section{B. Interrupt service routines}

Interrupt services handle events originating in peripheral modules of the main microcontroller. The firmware implements three interrupt handlers: (1) the timer interrupt with the period of $1 \mathrm{~ms}$ where data acquisition and filtering task are processed; (2), (3) serial interface 1 and 2 interrupts which occur whenever a character from the supervisory system is received.

\section{Communication protocol}

The device implements an ASCII character-based communication protocol that was used due to a simple and effective cooperation with many software environments utilised in process control and measurement areas. Moreover, a very useful advantage of this solution is the possibility to control the converter unit by using any terminal program included in most operating systems.

Each command starts with ' $\sim$ ' character followed by one character length command code. After that, argument fields can be placed (if the command requires them) consisting of unsigned integer numbers in the range of 0 to 65535 separated by spaces (ASCII code 32). Each command and device response is terminated by the CR and LF sequence with ASCII codes 13 and 10 . The device responds with ' $\sim$ ' character followed by one or more integer numbers each separated by spaces. In the case that the response does not contain any numerical data, it sends confirmation string " $\sim \mathrm{AC}\langle\mathrm{CR}\rangle\langle\mathrm{LF}\rangle$ ". If the command is unknown or invalid, the device responds with the error message in the format " $\sim \mathrm{Ex}<\mathrm{CR}><\mathrm{LF}>$ ", where $\mathrm{x}$ represents the error code number. The command for the periodical sending of the selected registers content represents a special case, where responses are sent automatically until this function is active. Summary of the implemented commands is given in Table III.

TABLE III IMPLEMENTED COMMANDS

\begin{tabular}{|c|c|}
\hline Command & Description \\
\hline " R <addr $><\mathrm{CRLF}>"$ & $\begin{array}{c}\text { Read value stored in the register at } \\
\text { address }\langle\text { addr }>\text {. }\end{array}$ \\
\hline " $\mathrm{W}<$ addr $><\mathrm{val}><\mathrm{CRLF}>"$ & $\begin{array}{c}\text { Write value <val> to the register at } \\
\text { address < }<\text { addr }>\text {. }\end{array}$ \\
\hline $\begin{array}{c}" \sim \mathrm{T}<\text { per }><\text { addr } 1><\text { addr } 2>\ldots \\
\quad<\text { addr } 8><\text { CRLF }>"\end{array}$ & $\begin{array}{l}\text { Activate automatic send function of } \\
\text { values stored in up to } 8 \text { selected } \\
\text { registers with the period <per>. }\end{array}$ \\
\hline " S <CRLF>" & $\begin{array}{l}\text { Deactivate automatic send function of } \\
\text { values stored in selected registers. }\end{array}$ \\
\hline " I <CRLF>" & $\begin{array}{l}\text { Send the converter unit firmware } \\
\text { version multiplied by } 10 .\end{array}$ \\
\hline
\end{tabular}

Communication parameters of the both UART interfaces are set to speed $115200 \mathrm{Bd}, 1$ start bit, 1 stop bit, no parity and none flow control. The USB1 interface is dedicated to channel 1 control, the USB2 one for channel 2 control of the converter unit. Nevertheless, it is possible to access any device register in read mode from the both communication interfaces.

\section{FUnCTIONALITY TEST}

The functionality and efficiency of the designed new unit has been proofed by dynamic response measurements, and obtained data have been compared to those received from the first evolution of the device. Namely, step responses yielding a second order model of the heating plant and control responses (by using the controller satisfying a finite number of discrete control steps) have been measured. Besides, the noise level has been evaluated in terms of the least mean squares and absolute values of measurement and control errors; and these data verify the superiority of this new evolution of the unit

As first, step responses have been measured. The initial steady state was reached for the input power $P_{0}=10 \%$ (of the maximum possible power) resulting in the steady-state temperature value of $T_{0}=48.6^{\circ} \mathrm{C}$. Then, a step change of $\Delta P=40 \%$ has been performed. The corresponding dynamical responses $\Delta T\left(t_{k}\right)$ (relatively to the steady state level) measured by the older version and the new version of the I/O converter unit are displayed in Figs. 13 and 14, respectively, with the sampling period of $\Delta t=t_{k+1}-t_{k}=1 \mathrm{~s}$.

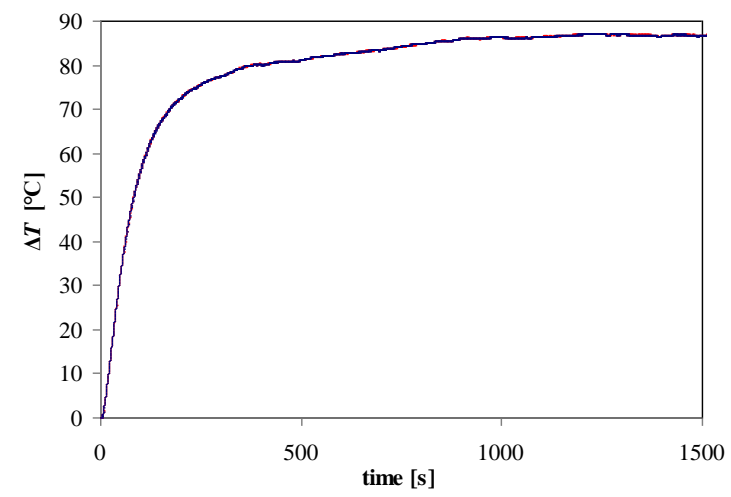

Fig. 13. Measured (red) and filtered (blue) controlled heating plant step responses for $\Delta P=40 \%$ for the first evolution of the unit

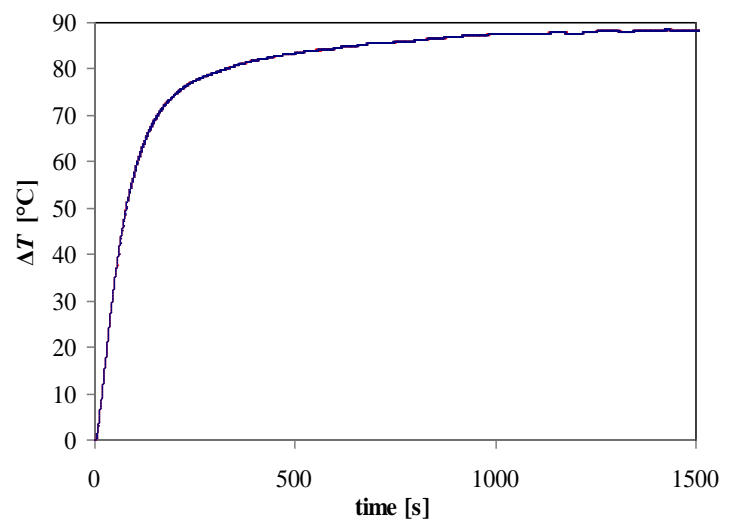

Fig. 14. Measured (red) and filtered (blue) controlled heating plant step responses for $\Delta P=40 \%$ for the first evolution of the unit

In these figures, filtered data are given as well, where the following simple averaging filter has been used:

$$
\Delta T_{F}\left(t_{k}\right)=1 / 3\left(\Delta T\left(t_{k-1}\right)+\Delta T\left(t_{k}\right)+\Delta T\left(t_{k+1}\right)\right)
$$


Now, the level of the noise can be evaluated with respect to the filtered data. We have chosen the following measures (criteria)

$$
\begin{aligned}
& J_{I S E}=\sqrt{\frac{\sum_{k=k_{0}}^{k_{N}} e_{F}\left(t_{k}\right)^{2}}{k_{N}-k_{0}}} \\
& J_{I A E}=\frac{\sum_{k=k_{0}}^{k_{N}} e_{F}\left(t_{k}\right)}{k_{N}-k_{0}} \\
& J_{M A X}=\max _{k \in\left[k_{0}, k_{N}\right.}\left|e_{F}\left(t_{k}\right)\right|
\end{aligned}
$$

where $e_{F}\left(t_{k}\right)=\Delta T\left(t_{k}\right)-\Delta T_{F}\left(t_{k}\right)$.

Results for the measured step responses with $k_{0}=2, k_{N}=1500$ are summarized in Table IV. Obviously, the new unit gives much less noise data. This fact is i.a. given by the $\mathrm{AD}$ converter with a better resolution (see Table II) and also by the use of the UBS serial communication.

Then, the obtained responses have served for the identification of the second order continuous time-model. Model parameters have been evaluated by using the least mean squared method to get the optimal time constants. The eventual model has read

$$
G(s)=\frac{1.93}{(4.17 \mathrm{~s}+1)(91.67 \mathrm{~s}+1)}
$$

The corresponding discrete-time model with the impulse period of $\Delta t=40 \mathrm{~s}$ and the zero-order hold has had the following form

$$
G(z)=\frac{0.623 z+0.0594}{z^{2}-0.6465 z+4.41 \cdot 10^{-5}}
$$

A linear proportional-difference-summation controller has been designed by using the method satisfying the finite number of control step (with an unbounded initial step) [11], [12] as

$$
R(z)=\frac{1.465 z^{2}-0.947 z+6.41 \cdot 10^{-5}}{z^{2}-0.913 z+0.087}
$$

Control responses as well as manipulated inputs measured by both the evolutions of the converter unit are displayed in Figs. 15 and 16.

For this data, we have measured the noise level in terms of the control error, i.e. we have applied formula (2) to $e\left(t_{k}\right)=T_{r e f}\left(t_{k}\right)-T\left(t_{k}\right)$ instead of $e_{F}\left(t_{k}\right)$ for selected time ranges in which holds that $\left|e\left(t_{k}\right)\right|<3{ }^{\circ} \mathrm{C}$. Hence, the eventual ranges have been: $k \in[400,999] \cup[1300,1799] \cup[2200,2600]$.

Since there have been two different setpoint values in the experiment, noise levels have been evaluated for the first and the third subrange, and for the second one, separately. Thus, let us define $I_{1}=[400,999] \cup[2200,2800], I_{2}=[1300,1799]$. The corresponding results are provided to the reader in Table V. It can be stated again that the new unit suffers less from the noise on the data output. Moreover, we have observed that the overall measured control error has been higher for a higher temperature reference when using the older version; however, the new unit has given approximately comparable data.
TABLE IV

NOISE LEVEL CRITERIA FOR MEASURED STEP RESPONSES

\begin{tabular}{ccc} 
Criterion & Evolution 1 & Evolution 2 \\
\hline$J_{I S E}$ & $8.15 \cdot 10^{-2}$ & $1.66 \cdot 10^{-2}$ \\
$J_{I A E}$ & $6.72 \cdot 10^{-2}$ & $1.46 \cdot 10^{-2}$ \\
$J_{M A X}$ & 0.21 & $4.07 \cdot 10^{-2}$ \\
\hline \hline
\end{tabular}

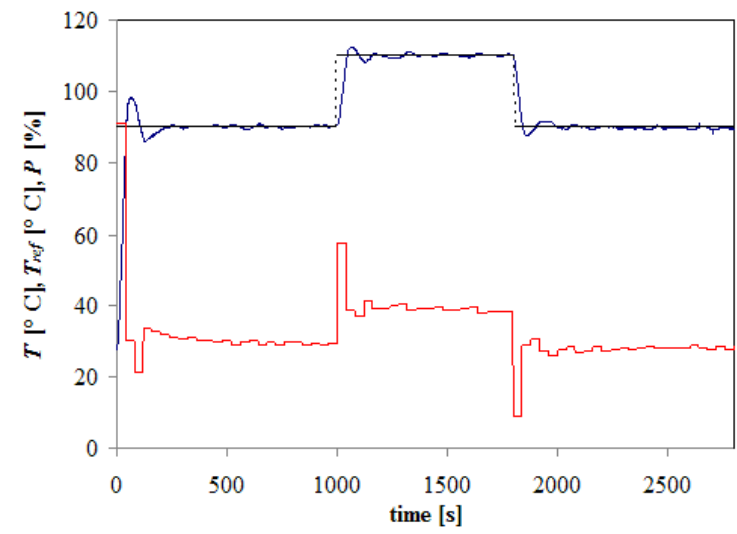

Fig. 15. The control response (blue), the manipulated input (red) and the reference signal (black) when controlling the heating plant - measured by the first evolution of the unit.

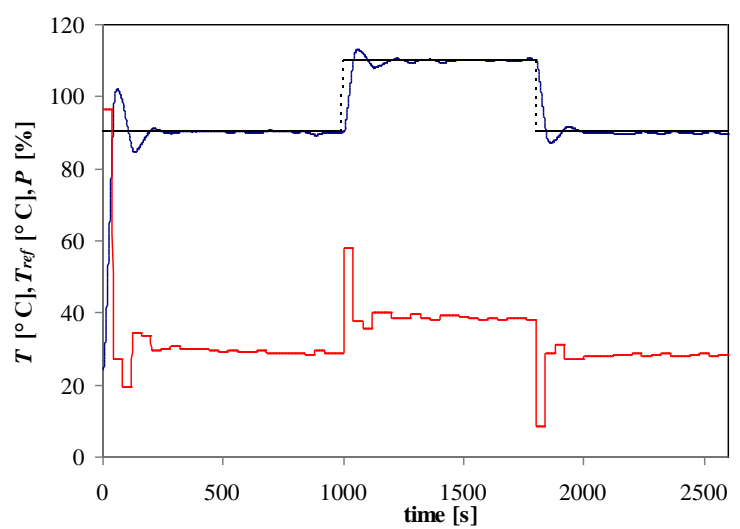

Fig. 16. The control response (blue), the manipulated input (red) and the reference signal (black) when controlling the heating plant - measured by the second (new) evolution of the unit.

TABLE V

NOISE LEVEL CRITERIA FOR MEASURED CONTROL RESPONSES

\begin{tabular}{ccc}
\hline \hline Criterion & Evolution 1 & Evolution 2 \\
\hline$J_{I S E}$ for $I_{1}$ & $3.35 \cdot 10^{-1}$ & $2.93 \cdot 10^{-1}$ \\
$J_{I S E}$ for $I_{2}$ & $3.80 \cdot 10^{-1}$ & $2.95 \cdot 10^{-1}$ \\
$J_{I A E}$ for $I_{1}$ & $5.22 \cdot 10^{-1}$ & $2.44 \cdot 10^{-1}$ \\
$J_{I A E}$ for $I_{2}$ & $5.86 \cdot 10^{-1}$ & $2.51 \cdot 10^{-1}$ \\
$J_{M A X}$ for $I_{1}$ & 1.72 & 0.61 \\
$J_{M A X}$ for $I_{2}$ & 2.95 & 0.57 \\
\hline \hline
\end{tabular}

Last but not least, a favorable input power consumption of the designed unit should be highlighted as well. The HM81152 power meter by Rohde\&Schwarz [13] has been used to detect the rated input power in the measurement mode of the appliance. Whereas the previous evolution of the unit has given the value of $5.86 \pm 0.04 \mathrm{~W}$, the new one has had $4.93 \pm 0.04 \mathrm{~W}$. Note that the obsolete converter has given $20.65 \pm 0.12 \mathrm{~W}$. 


\section{CONCLUSION}

This paper has been focused on the description of the appearance and properties of the second evolution of the innovated I/O data acquisition, converter and control unit for laboratory measurements on heating models. The appliance can also be used as a multipurpose (universal) device due to the unified analog input of $0-10 \mathrm{~V}$ DC. Other basic characteristics, desirable features and main improvements are the following: Crucial features of the preceding design have been preserved such that the novel device can work in the compatibility mode. The innovated HW structure includes: a motherboard with the microcontroller; $2 x$ the USB interface (enabling the better compatibility with notebooks (laptops) compared to RS232 without the necessity of an external USB to RS232 converter); a safe power supply and 8 connectors for expansion modules (the wiring has been reduced); the $\mathrm{A} / \mathrm{D}$ converter resolution is increased to 14 bits, the D/A converter has $16 \mathrm{~b}$ resolution, the digital output can work with up to $32 \mathrm{~b}$ precision; more accurate operation amplifiers are mounted on analog circuits compared to the preceding version. Noise is reduced also due to the direct serial link; the OLED provides the user with much better readability, response and energy consumption compared to the LCD with LED backlight. The serial interface enables to transfer control signals and measured values digitally without the necessity of a data acquisition card. A significant advantage of the device can also be seen in its low price, which has made the unit easily reachable for a wide range of potential users. Beside the description of $\mathrm{HW}$ components, operational and functional properties together with firmware services have been given in the paper. A laboratory measurement and control experimental example has verified beneficial features of the device.

In the future, the authors plan to equip the unit with modules for the remote (internet) communication, GPRS module and to programme more SW functions for students' practising of control task in the laboratory.

\section{REFERENCES}

[1] D. Mahoney, B. Young, and W. Svrcek, "A completely real time approach to process control education for process systems engineering students and practitioners," Comput. Chem. Eng., vol. 24, pp. 1481-1484, 2000.

[2] S. Postalcioglu, E. D. Bolat, and K. Erkan, "Temperature control using autotuning PID controller for control education," in Proc. WSEAS Int. Conf. Signal Processing, Robotics and Automation, Madrid, Spain, 2006, pp. 131-134.

[3] L. Pekař, P. Dostálek, P. Navrátil, and Z. Oborný, "Low-cost intelligent educational laboratory temperature data acquisition and control device," Int. J. Circ. Sys. Signal Pr., vol. 9, pp. 103-112, 2015.

[4] G.-Q. Liu, "A temperature-measuring system on the gun-barrel bore of armor-artillery base on 80C196 MCU," Adv. Mat. Res., vol. 562-564, pp. 1920-1923, 2012.

[5] P. Doležel, V. Vašek, D. Janáčová, K. Kolomazník, and M. Zálešák, "Modeling and microcontroller control of raw hide soaking in tannery industry," Int. J. Math. Mod. Meth. Appl. S., vol. 5, no. 7, pp. 1225-1232, 2011.

[6] S. Plšek and V. Vašek, "The control system for the production of biodiesel," Int. J. Circ. Sys. Signal Pr., vol. 6, no. 5, pp. 342-349, 2012.

[7] M. Staněk, D. Maňas, D. Maňas, J. Navrátil, and A. Škrobák, "SW and HW optimization of injection molding process," Int. J. Mech., vol. 8, no. 1, pp. 85-92, 2014.

[8] P. Dostálek, V. Vašek, and J. Dolinay, "Simple microcontroller based mains power analyzer device," Int. J. Circ. Sys. Signal Pr., vol. 7, no. 4, pp. 214-221, 2013.

[9] J. Dolinay, V. Vašek, and P. Dostálek, "Utilization of simple real-time operating system on 8-bit microcontroller," Int. J. Math. Mod. Meth. Appl. S., vol. 5, no. 7, pp. 785-796, 2011.

[10] MCF51AC256 Series ColdFire Microcontroller Data Sheet: Technical Data (cited 2016, October 12), NXP Semiconductors, Inc. [Online]. Available: http://www.nxp.com/files/32bit/doc/data_sheet/MCF51AC 256.pdf.

[11] Š. Kozák, Linear Digital Systems I, Bratislava: STU Bratislava, 1993 (in Slovak).

[12] J. Balátě, Automatic Control, 2nd ed., Prague: BEN Prague, 2004, 664 p. (in Czech).

[13] HM8115-2 Power Meter - Overview (cited 2016, October 12), Rohde\&Schwarz [Online]. Available: https://www.rohdeschwarz.com/us/product/hm8115-productstartpage_63493-44099.html. 